\title{
Influence of Intrinsic and Extrinsic Motivation on Employee's Task Performance
}

\author{
Arooj Makki ${ }^{1} \&$ Momina Abid ${ }^{2, *}$ \\ ${ }^{1}$ Department of Applied Psychology Bahauddin Zakariya University, Multan \\ ${ }^{2}$ Psychologist, Special Education Department Government of the Punjab, Pakistan \\ *Correspondence: Special Education Department Government of the Punjab, Pakistan E-mail: \\ Mominaabid11@gmail.com
}

Received: January 13, 2017

Accepted: January 20, 2017 Online Published: January 25, 2016

doi:10.5430/sass.v4n1p38

URL: http://dx.doi.org/10.5430/sass.v4n1p38

\begin{abstract}
Intrinsic and extrinsic motivation is important determinant of employee's task performance as it represents the level of motivation of employees to their work and company. This study examined the influence of intrinsic and extrinsic motivation on employees' task performance and also aimed to find out the difference between males and females on task performance based on their intrinsic and extrinsic motivation. The Work Preference Inventory (Amabile, T. M., et al., 1994) and Job Performance Scale (Goodman, \& Svyantek, 1999) was used to gather data. It was predicted that intrinsic and extrinsic motivation will be positively correlated with employees' task performance and will have impact on employees' task performance. The results showed that intrinsic and extrinsic motivation has positive correlation with employee's task performance and intrinsic and extrinsic motivation has impact on employee's task performance. Findings also show that females are more intrinsically motivated as compared to males.
\end{abstract}

Keywords: intrinsic motivation, extrinsic motivation, task performance

\section{Introduction}

Motivation is a theoretical construct used to describe behavior. It represents the reasons for people's activities, wishes, and needs. Motivation can also be described as one's direction to activities or what causes a person to want to repeat a behavior again and vice versa. Most concepts of motivation indicate these concerns by viewing motivation as a unitary trend, one that is different from very little motivation to act to great deal of it. Motivation is a word that is part of the popular tradition as few other psychological concepts are. Motivation can be divided into two different concepts known as Intrinsic (internal) motivation and Extrinsic (external) motivation. Intrinsic motivation has been studied since the early 1970s. Intrinsic motivation is the self-desire to find new things and new challenges, to assess one's potential, to observe and to gain knowledge. It is influenced by an interest or enjoyment in the task itself, and exists within the individual rather than depending on external pressures or a desire for reward. Extrinsic motivation refers to the performance of an activity in order to gain a desired outcome and it is the opposite of intrinsic motivation. Extrinsic motivation comes from influences outside of the individual.

\subsection{Intrinsic Motivation}

In 1973 Lepper et al. studied that intrinsic motivation represents a motivation to indulge in an activity purely for the reason of the activity itself. When individuals are intrinsically motivated, they practice activities for the interest and enjoyment those activities provide (Csikszentmihalyi, 1975), and they typically perform at relatively high levels (Amabile, 1996; Grolnick \& Ryan, 1987). Intrinsic motivation has appeared as an important phenomena for educators a natural wellspring of learning and achievement that can be systematically undermined by parent and teacher practices (Ryan \& Stiller, 1991). Because intrinsic motivation results in high-quality learning and creativity, it is especially important to detail the factors and forces that engender versus undermine it. Findings suggest that perceiving oneself as competent at an activity often promotes enjoyment of that activity as does the presence of "optimal" challenges (Csikszentmihalyi et al. 1975) and valuing competence in the activity (Elliot et al., 2000). 


\subsection{Extrinsic Motivation}

External motivation reveals a reason to participate in an action as a means to an end rather than an end in itself (Pintrich \& Schunk, 1996). When individuals are extrinsically motivated, they take part in actions in search for benefits they wish such as money, reputation, or publication of journals. In the traditional literary works, extrinsic motivation has generally been recognized as a light and poor (even if powerful) type of inspiration that differences with implicit inspiration (e.g., deCharms, 1968). Extrinsic motivation has obtained less research interest, here too the main concentrate has been on the situational aspects that impact it, such as performance-contingent benefits (which can improve extrinsic motivation; Eisenberger \& Rhoades, 2001) and task-intrinsic benefits (which can reduce extrinsic motivation; Kruglanski, 1975).

\subsection{Task Performance}

Employee's task performance was defined as what a worker perform or does not perform. Task performance of employees includes relevance, quantity, quality of output, and cooperativeness. Task performance relates to transforming raw materials into the goods and services which are specific to the job, the core technical skill. Task efficiency contains actions that lead to the primary modification and maintenance activities in an organization, such as producing products, selling products, obtaining stock, handling employees, or providing services (Motowidlo \& Schmit, 1999). Task performance that is recommended by the company or its associates and optional work behaviors that lie under the control of the employee (e.g., pro-social actions (Puffer, 1987), citizenship behaviors (Podsakoff, MacKenzie, Moorman, \& Fetter, 1990). Task performance is described as work behavior that is related to "the organization's technical core, either by executing its technical processes or by maintaining and servicing its technical requirements" (Motowidlo, Borman, \& Schmit, 1997), and it is generally considered as essential or in-role obligations that employees are employed to perform in return for their settlement offers (Rousseau \& Recreational areas, 1993).

There is evidence that constant, relatively enduring motivational orientations at the trait level may also apply considerable influence on state-level experience and behavior. For example, in a study which used the Experience Sampling Method (Larson \& Csikszentmihalyi, 1983) to evaluate psychological and behavior styles associated with the academic achievement of high school students, Wong and Csikszentmihalyi (1991) found that students' "work motivation" a composite "higher order" trait positively associated with achievement motivation and negatively associated with play and impulsivity (from the PRF form; Fitzgibbons, 1984) — was positively related with how long the students spent studying. Additionally, using the Causality Orientations Scale (Deci \& He, 1985) to evaluate variations in autonomy, controlled, and interpersonal orientations, studies have discovered that these three individual differences can have significant consequences for motivation at the situational level (e.g., Koestner, Bernieri, \& Zuckerman, 1992).

Studies have established that the relative importance given to task compared to contextual behaviors has important implications for the definition of performance that is used in forming human resources decisions. For example, Murphy and Shiarella (1997) revealed that the credibility of selection procedures relies on the relative values placed on task and contextual performance. Studies have also revealed that managers vary in the relative weight they give to the two dimensions when evaluating an employee's overall participation to the company (e.g., Brown, 2001; Rotundo \& Sackett, 2002). Decisions about promotions or other rewards, therefore, may depend on the relative values that manager's place on the task and contextual performance-relevant beahviors revealed by their employees. Other research has revealed that the relative importance that an organization places on task and contextual performance may influence negative impact and minority hiring (Hattrup, Rock, \& Scalia, 1997).

\section{Objectives}

1. To assess the correlation between intrinsic and extrinsic motivation and employee task performance.

2. To assess the impact of intrinsic and extrinsic motivation on employee task performance.

3. To investigate the difference between male and female employees on intrinsic motivation.

\section{Hypothesis}

1. Intrinsic and extrinsic motivation will be positively correlated to employee task performance.

2. Intrinsic and extrinsic motivation will have impact on employee task performance.

3. Intrinsic and extrinsic motivation and employee task performance will vary in term of gender. 


\section{Method}

\subsection{Research Design}

For the purpose of the study survey type research design had been used. It was a correlational study that was used to assess the relationship among extrinsic and extrinsic motivation and task performance. Purposive sampling technique was used in this study.

\subsection{Participants}

Participants included 150 employees ( 80 males, 70 females), some of them were doing job in government and private sector. The researcher had chosen sample from different areas and industries. The age range of the participants of this study was 20-70 years. The participants differed according to age, gender, job designation, marital status, and job place.

\subsection{Instruments}

1. Work preference inventory

2. Task performance scale

Work Preference Inventory. The work preference inventory was developed by Amabile, T. M., Hill, K. G., Hennessey, B. A., \& Tighe, E. M. (1994). The WPI consists of 30 questions designed to assess employee overall intrinsic and extrinsic motivational orientations toward their work. The intrinsic primary scale is sub - divided into the Challenge and Enjoyment secondary scales. The extrinsic primary scale is sub - divided into the Outward and Compensation secondary scales. The score on each scale is computed as the mean of each item on that scale. There is 4-point rating scale with $1=$ Never true of me, $2=$ almost never true of me, $3=$ almost always true of me, 4=Always true of me. Simply count the number of yes answers and average score was calculated

Job Performance Scale. Job performance scale was developed by Goodman, \& Svyantek, (1999). It has two sub-division contextual and task performance. Task performance has consisted of 9 items designed to analyze the level of employee's task performance. Each item is cored on four point likert scale; high score signifies higher level of task performance.

\subsection{Procedure}

Information has been accumulated by using survey questionnaire, given to employees. Information was collected to different age group children (20 to 65). The questionnaire consisted of 2 variables Work preference inventory and task performance scale in the booklet from along with consent form and demographic information. The employees were informed with regards to the purpose of research and have been directed how to populate this weighing scales. Participants have been advised to help all the items seriously. Participants have been likewise provided confidence in which info would be discreet. SPSS 17 version (Statistical Package for Social Sciences) has been used for the descriptive and inferential statistical analysis of the data collected from the parents and their children.

\section{Results}

Table 1. Correlation between Intrinsic and Extrinsic Motivation and Employee's Task Performance

\begin{tabular}{cccc}
\hline & Intrinsic Motivation & Extrinsic Motivation & Task Performance \\
\hline Intrinsic Motivation & - & & \\
Extrinsic Motivation & $.360^{* *}$ & - & \\
Task Performance & $224^{* *}$ & $356^{* *}$ & - \\
\hline
\end{tabular}

$\mathrm{N}=150, * * * \mathrm{p}<0.001$

Values depicted in table 1 show that there is significant positive correlation between Intrinsic and Extrinsic motivation and employee's task performance. 
Table 2. Impact of Intrinsic and Extrinsic Motivation on Employee's Task Performance

\begin{tabular}{lccccc}
\hline Predictors & $B$ & Std. Error & Beta & $t$ & $p$ \\
\hline (Constant) & 14.088 & 3.289 & & 4.283 & $.000^{* * *}$ \\
Intrinsic Motivation & .268 & .068 & 224 & 3.921 & $.000^{* * *}$ \\
Extrinsic Motivation & .090 & .067 & 356 & 1.344 & $.001^{*}$ \\
\hline
\end{tabular}

Note. $\quad R^{2}=0.140$, Adjusted $R^{2}=0.129,(F=11.985) * p<=0.05, * * * p<=0.001$

The above table shows the results of ANOVA for evaluating the impact of intrinsic and extrinsic motivation on employees' task performance. In the table we can see that the value of p less than $\alpha$ level which shows that intrinsic and extrinsic motivation has significant impact on employee's task performance.

Table 3. Mean, Standard Deviation and t Value for Scores of Gender on Task Performance Scale

\begin{tabular}{cccccc}
\hline Group & $\mathrm{N}$ & $\mathrm{M}$ & $\mathrm{SD}$ & $\mathrm{T}$ & $\mathrm{p}$ \\
\hline Male & 80 & 29.33 & 3.36 & & \\
& & & & -1.230 & .221 \\
Female & 70 & 30.05 & 2.60 & & \\
\hline
\end{tabular}

Note. $\mathrm{df}=148 \mathrm{p}>0.05$

Table 3 shows the Mean, $\mathrm{SD}, \mathrm{t}$ value of comparison of male and female on task performance. As shown by the $\mathrm{p}$ value which is greater than the level of significance (0.05), it is clear that there is no significant difference between male and female on task performance.

Table 4. Mean, Standard Deviation and $\mathrm{t}$ Value for Scores of Gender on Intrinsic Motivation

\begin{tabular}{cccccc}
\hline Group & $\mathrm{N}$ & $\mathrm{M}$ & $\mathrm{SD}$ & $\mathrm{t}$ & $\mathrm{p}$ \\
\hline Male & 80 & 43.17 & 3.99 & & \\
& & & & -2.011 & .046 \\
Female & 70 & 45.58 & 3.10 & & \\
\hline
\end{tabular}

Note. $\mathrm{df}=148 \mathrm{p}>0.05$

Table 4 shows the Mean, SD, $t$ value of comparison of male and female on intrinsic motivation. As shown by the $\mathrm{p}$ value which is lower than the level of significance (0.05), it is clear that there is significant difference between male and female on intrinsic motivation. Findings show that females are more intrinsically motivated as compared to males.

Table 5. Mean, Standard Deviation and t Value for Scores of Gender on Extrinsic Motivation

\begin{tabular}{cccccc}
\hline Group & $\mathrm{N}$ & $\mathrm{M}$ & $\mathrm{SD}$ & $\mathrm{t}$ & $\mathrm{p}$ \\
\hline Male & 80 & 41.37 & 4.09 & & \\
& & & & -1.509 & .134 \\
Female & 70 & 42.47 & 3.16 & & \\
\hline
\end{tabular}

Note. $\mathrm{df}=148 \mathrm{p}>0.05$

Table 5 shows the Mean, SD, $t$ value of comparison of male and female on extrinsic motivation. As shown by the $p$ value which is greater than the level of significance (0.05), it is clear that there is no significant difference between male and female on extrinsic motivation. 


\section{Discussion}

The present study was undertaken to investigate the impact of Intrinsic and extrinsic motivation on employees' task performance. It also explored the correlation between intrinsic and extrinsic motivation and task performance. This research was conducted to find whether intrinsic and extrinsic motivation has any relationship with employee's task performance among employees. The critical analysis of tabulated results leads to following inferences.

Result of first table was based on hypothesis that intrinsic and extrinsic motivation is positively correlated with task performance. So this study supports the result that there is a significant positive relationship between employees' task performance and intrinsic and extrinsic motivation. This study also showed that there is a significant impact of intrinsic motivation and extrinsic motivation on task performance. This can be proved by previous study which states that when individuals are intrinsically motivated, they practice activities for the interest and enjoyment those activities provide (Csikszentmihalyi, 1975), and they typically perform at relatively high levels (Amabile, 1996; Grolnick \& Ryan, 1987) and when individuals are extrinsically motivated, they take part in actions in search for benefits they wish such as money, reputation, or publication of journals (deCharms, 1968). Thus consistent with previous research, our findings demonstrate that employees who are both intrinsically and extrinsically motivated show best on task performance.

The results depicted in this study elaborate that intrinsic and extrinsic motivation and employee's task performance vary according to demographic variables which shows that females are more intrinsically motivated as compared to males, and there is no significant difference between male and female on task performance. This can be proved by previous study which states that when individuals are intrinsically motivated, they pursue activities for the interest and enjoyment those activities provide (Csikszentmihalyi, 1975).

This study also revealed that extrinsic motivation will not vary among male and female employees which can be proved by previous study which stated that extrinsic motivation has generally been recognized as a light and poor (even if powerful) type of inspiration that differences with implicit inspiration (e.g., deCharms, 1968).

\section{Conclusion}

The current study entitled Influence of Intrinsic and Extrinsic Motivation on Employee's Task Performance: Comparison based on Gender differences confirm the fact that the employees with higher level of intrinsic and extrinsic motivation are better at task performance. Research indicated that there is a positive correlation between intrinsic and extrinsic motivation and employee's task performance. The results depicted in this study elaborate that intrinsic and extrinsic motivation and employee's task performance vary according to demographic variables which shows that according to the gender variable as described there is no significant difference between male and female on extrinsic motivation, there is significant difference between male and female on intrinsic motivation. Findings show that females are more intrinsically motivated as compared to males, and there is no significant difference between male and female on task performance.

\section{References}

Abuhamdeh, Csikszentmihalyi. (1975). Intrinsic and Extrinsic Motivational Orientations in the Competitive Context: An Examination of Person-Situation Interactions. University of Chicago, Claremont Graduate University.

Befort, Keith. (2003). Valuing Task and Contextual Performance: Experience, Job Roles, and Ratings of the Importance of Job Behaviors. Applied H.R.M. Research, 8(1), 17-32.

Broeck, Vansteenkiste, Witte, Soenens, Lens. (2010). Capturing autonomy, competence, and relatedness at work: Construction and initial validation of the Work-related Basic Need Satisfaction scale. Journal of Occupational and Organizational Psychology, 83, 981-1002. https://doi.org/10.1348/096317909X481382

Cerasoli, C. P., Nicklin, J. M., \& Ford, M. T. (2014, February 3). Intrinsic Motivation and Extrinsic Incentives Jointly Predict Performance: A 40-Year Meta-Analysis. Psychological Bulletin.

Deci, E. L. (1975). Intrinsic motivation. New York: Plenum. https://doi.org/10.1007/978-1-4613-4446-9

Deci, E. L., Eghrari, H., Patrick, B. C., \& Leone, D. R. (1994). Facilitating internalization: The self-determination theory perspective. Journal of Personality, 62, 119-142. https://doi.org/10.1111/j.1467-6494.1994.tb00797.x

Deci, E. L., Koestner, R., \& Ryan, R. M. (1998). Extrinsic rewards and intrinsic motivation: Clear and reliable effects. Unpublished manuscript, University of Rochester. 
Hayamizu, T. (1997). Between intrinsic and extrinsic motivation: Examination of reasons For academic study based on the theory of internalization. Japanese Psychological Research, 39, 98-108. https://doi.org/10.1111/1468-5884.00043

Ryan, Deci. (2000). Intrinsic and Extrinsic Motivations: Classic definitions and new directions. Contemporary Educational Psychology, 25, 54-67. https://doi.org/10.1006/ceps.1999.1020

Silman. (2014). Work-related basic need satisfaction as a predictor of work engagement among academic staff in Turkey. South African Journal of Education, 34(3), 1-5. https://doi.org/10.15700/201409161119

Rizwan, Khalid, Ahmad, Iram, Asad. (2015). Effect of intrinsic rewards on task performance of employees: Mediating role of motivation. International Journal of Organizational Leadership, 4, 33-46. 